\section{Optic Nerve}

John E. Mendoza

Department of Psychiatry and Neuroscience, Tulane Medical School and SE Louisiana Veterans Healthcare System, New Orleans, LA, USA

\section{Definition}

That portion of the visual pathway that extends from the eye to the optic chiasm. The optic nerve consists of the axons of the ganglion cells of the retina. With a few exceptions, most then travel uninterrupted to the lateral geniculates. However, only that portion which lies between the optic disc and the chiasm is referred to as the optic nerve. The post-chiasmatic fibers are known as the optic tracts. Because of the partial crossing that takes place in the chiasm, the optic nerve contains fibers from one eye, whereas the optic tract contains fibers from both eyes. Consequently a lesion involving an optic nerve can result in monocular visual loss.

\section{Cross-References}

- Optic Chiasm

- Visual System 